\title{
Ferenczi e a constituição das formas de expressão
}

\author{
Leonardo Câmara ${ }^{\text {** }}$ (1) \\ Regina Herzog ${ }^{b}$ \\ a Universidade Federal de São Carlos, Departamento de Psicologia, São Carlos, SP, Brasil \\ ${ }^{b}$ Universidade Federal do Rio de Janeiro, Rio de Janeiro, RJ, Brasil
}

Resumo: Subsiste, ao longo de toda a obra de Sándor Ferenczi, uma preocupação com a dimensão do corpo na experiência psicanalítica, concebendo-o predominantemente sob o viés da expressão. Este artigo visa apresentar uma leitura, com base em sua teoria, sobre a constituição dos múltiplos modos de expressão. Para isso, são propostas seis ideias que se organizam em duas séries paralelas e complementares. A primeira envolve as noções de onipotência, catástrofe e regressão; a segunda agrupa as ideias de condição, adaptação e complexificação.

Palavras-chave: Ferenczi, expressão, corpo, psicanálise.

Atualmente, o psicanalista húngaro Sándor Ferenczi (1873-1933) é lembrado, sobretudo, por suas inovações técnicas e por sua teoria do trauma. Uma região de sua obra, talvez menos explorada, concerne às suas concepções sobre o corpo. Claro está que as experimentações técnicas e, mais ainda, a teoria do desmentido e da clivagem se sobrepõem, em alguma medida, à questão do corpo. Entretanto, na via contrária do desenvolvimento da obra ferencziana, tende-se a considerar o corpo como elemento acessório, isto é, secundário àqueles outros dois tópicos. Soma-se a isso o fato de a ideia de linguagem ser utilizada para entender Ferenczi, tendo como consequência, grosso modo, em se qualificar o corpo e suas manifestações como um índice de déficit simbólico ou representacional.

Consideramos que essa perspectiva encontra limitações quando empreendemos, parodiando Lacan, "um retorno a Ferenczi”. De fato, suas concepções sobre o corpo são de tal forma singulares e surpreendentes que, para conseguirmos nos aproximar delas, necessitamos pôr em suspensão certas coordenadas de leitura, agora naturalizadas, do corpus psicanalítico, a exemplo da linguagem. Em um contexto maior de pesquisa ${ }^{1}$, optamos pelo uso do termo "expressão", pois nos parecia se adequar melhor ao posicionamento epistemológico de Ferenczi, que identificamos como monista e materialista (Câmara \& Herzog, 2014). Os argumentos que corroboram tanto o emprego desse termo quanto a suspensão da ideia de linguagem se encontram em outras publicações, para as quais remetemos o leitor interessado (Câmara, 2018, 2021; Câmara, Herzog, \& Canavêz, 2018).

\footnotetext{
* Endereço para correspondência: lcpcamara@ufscar.br

1 Os resultados da pesquisa citada, parcialmente apresentados neste artigo, encontram-se publicados integralmente no livro Ferenczi e a psicanálise: corpo, expressão e impressão (Câmara, 2021).
}

No que diz respeito a este artigo, seu propósito imediato é desenvolver uma perspectiva, com base na teoria ferencziana, sobre a constituição dos múltiplos modos de expressão. Para cumprir esse objetivo, são propostas seis ideias ou noções, em nosso entender fundamentais, que se organizam em duas séries paralelas e complementares. A primeira série, que envolve as ideias de onipotência, catástrofe e regressão, trata de uma dimensão longitudinal da narrativa ferencziana; a segunda série, composta pelas ideias de condição, adaptação e complexificação, concerne a uma dimensão transversal da mesma. O propósito mediato, por sua vez, é fazer ver uma teoria da expressão que, acreditamos, marca uma presença virtual na obra ferencziana e cujas potencialidades não podem ser ignoradas, uma vez que Ferenczi propõe a abertura da psicanálise à multiplicidade expressiva do corpo, colocando em questão a hegemonia da linguagem verbal como condição de possibilidade da experiência psicanalítica.

\section{Um estudo da forma ${ }^{2}$}

O problema da expressão e de suas múltiplas formas surge relativamente cedo na teoria ferencziana, sendo o texto "O desenvolvimento do sentido de realidade e seus

2 A julgar pelos sentidos que adquiriu ao longo da história da filosofia, o termo forma traz consigo diversos elementos potencialmente problemáticos para este estudo. O maior deles, a nosso ver, é entender, por forma, uma entidade apriorística e ideal para a qual a matéria tenderia a adquirir seus contornos, o que não se coaduna à proposta de Ferenczi. Outros termos, que guardam em nossa língua certas relações sinonímicas, poderiam ser igualmente utilizados, como modo e maneira. Entretanto, eles também guardam certas complicações, sobretudo o termo "modo". Ferenczi utiliza com certa frequência a palavra Ausdrucksbewegungen, "movimentos de expressão", e algumas vezes Ausdrucksmittels, "meios de expressão", que parece ser mais adequado (Ferenczi, 1912/1927, 1919/1939). Decidimo-nos, enfim, por utilizar os termos de maneira intercambiável. 
estágios", escrito ao longo de 1912 e publicado no ano seguinte, seu núcleo. Valendo-se de "uma espécie de empatia" (einer Art Einfühlung) que sente em relação à vida infantil, Ferenczi (1913/1992) busca nesse trabalho, em linhas gerais, fazer uma reconstrução de como a criança se relaciona com a ilusão e a realidade, a onipotência e a catástrofe, a regressão e a invenção (Ferenczi, 1926/1927,1926/1993). Apesar de o objeto central de suas reflexões ser justamente o que o título do texto propõe - os desdobramentos daquilo que chama de "sentidos de realidade"-, sustentamos que Ferenczi descreve, em tal contexto, a origem, transformação, complexificação e interação de diversas formas de expressão (Câmara, 2021). Todas elas se dão nas relações que envolvem a criança e o mundo - o que não poderia ser diferente, visto que o lugar onde os movimentos expressivos se expandem, mesmo quando no seio do mais radical solipsismo da onipotência infantil, é a relação com o outro, zona de misturas e diferenciações, crises e adaptações. Além disso, todas elas envolvem o corpo, desde os movimentos corporais mais visíveis até as formas de expressão que parecem dele prescindir, como o pensamento.

Da narrativa composta por Ferenczi, deriva uma série de elaborações que se dispersam e se ramificam em momentos variados da obra, buscando enfrentar diferentes questões, sejam elas de ordem clínica ou teórica. Não há dúvida de que "Thalassa: ensaio sobre a teoria da genitalidade" (1924) consiste no trabalho que mais claramente desenvolve hipóteses e intuições deflagradas em "O desenvolvimento do sentido de realidade", muitas delas surgidas de um esforço de imaginação que levou Ferenczi (1913/1992), em suas palavras, às "lonjuras fabulosas do passado" (p. 52). Entretanto, outros textos de sua autoria elaboram questões e acrescentam elementos que trazem ainda mais substância a uma virtual teoria da expressão, tendo como base o citado texto publicado em 1913. A título de exemplo, o modo de expressão por gestos corporais adquire, progressivamente e até o final de sua vida, uma inegável importância para tratar de problemas clínicos e teóricos os mais diversos.

A questão de base que Ferenczi coloca para chegar ao problema das formas de expressão inicia-se na tradicional divisão entre conteúdo e forma. Com efeito, sob sua perspectiva, as investigações sobre a libido e a pulsão sexual levaram Freud a descobrir o conteúdo ou, ainda, o teor (Gehalt) dos sintomas neuróticos (Ferenczi, 1913/1927): resultado de uma solução de compromisso que levou o conflito a um ponto de equilíbrio (ainda que precário), o sintoma representa um desejo recalcado. Em outras palavras, o conteúdo de um sintoma é um desejo que, inadmissível à consciência, foi recalcado e, lutando para se expressar, se vale de relações simbólicas para camuflar-se e ganhar a consciência. Deve-se à interpretação o procedimento com o qual se consegue traduzir o conteúdo latente, escondido, recalcado de um fenômeno psíquico. Não foi senão por meio dela que Freud estabeleceu esta que continua sendo uma de suas construções teóricas mais penetrantes: o sintoma representa a atividade sexual do neurótico (Freud, 1905/2006).
Uma vez esclarecido o teor dos sintomas, restava (ou surgia) outra pergunta, pergunta que constitui a espinha dorsal de "O desenvolvimento do sentido de realidade e seus estágios": por que um sintoma se apresenta, se expressa de determinada forma? (Ferenczi, 1913/1992). Deslocamento notável do problema. A questão não é mais entender o que o sintoma representa, não é interpretar seu conteúdo recalcado, mas como e por que ele se apresenta de diferentes modos. Não mais um problema sobre o conteúdo, sobre as profundidades, sobre as intrincadas associações que devem ser interpretadas, mas um problema sobre a forma, sobre a superfície, sobre isso que se apresenta e se exprime na atualidade do momento sem véus, sem artifícios.

$\mathrm{Na}$ clássica distinção entre histeria e neurose obsessiva, por exemplo, o sintoma histérico apelaria ao plano corporal por meio de conversões, ao passo que o neurótico obsessivo seria invadido e habitado por um caudal de ideias e pensamentos incoercíveis (Freud, 1894/2006, 1926/2014). Estariam aí expostas duas apresentações sintomáticas que representariam ou seriam representantes, no fim das contas, de um mesmo objetivo, de um mesmo teor, de um mesmo conteúdo: um desejo recalcado.

Ainda que não tenha colocado o problema nesses termos, pode-se dizer que Freud tentou abordá-lo questionando não como o sintoma se apresenta per se, mas quem o produz: daí suas múltiplas tentativas de descrever aquilo a que se conveio chamar de "escolha da neurose" (Freud, 1912/2006). Cada formação sintomática estaria vinculada a uma configuração clínica específica, tal como, por exemplo, a conversão seria um mecanismo próprio da neurose histérica. O que mais importaria, então, seria entender o tipo de neurose, onde se deram as fixações libidinais, para chegar à forma como um sintoma se expressa. Ferenczi, por sua vez, resolveu desenvolver a questão a contrapelo dessa maneira de colocar o problema.

No lugar de se preocupar com o que se oculta, com o que uma coisa pode realmente dizer, ele escolheu se deter sobre a Erscheinungsform, a forma aparente manifesta - dos sintomas (Ferenczi, 1913/1927). Não é por outro motivo que, em "O desenvolvimento do sentido de realidade e seus estágios", seu ponto de partida, mais do que o sintoma de onipotência da neurose obsessiva, é a "forma especifica (der eigentümlichen Erscheinungsform) em que esses sintomas obsessivos se apresentam: devemos admitir que eles já constituem em si mesmos um problema" (Ferenczi, 1913/1992, p. 40, grifos nossos). Para abordar o problema sobre a forma com que o sintoma se apresenta, Ferenczi entende ser necessário fazer a reconstrução da história de como o eu se afirma e produz maneiras de se afirmar frente às condições cada vez mais complexas impostas pela realidade - condições estas que parecem pôr em xeque, em diferentes frentes e em diferentes momentos, a possibilidade de se fruir de um sentimento de onipotência.

Ao desviar a atenção do conteúdo para a forma, da representação para a apresentação, tornou-se necessário 
fazer ainda o seguinte: em vez de seguir as múltiplas formas até alcançar o teor único de onde elas derivam e estão referidas, Ferenczi embrenhou-se no múltiplo em toda sua dispersão e variação. Isso o levou a inaugurar um gesto que moldará decisivamente sua trajetória: a forma pela qual um sintoma se apresenta não precisa estar adstrita a determinada configuração clínica. Se se insiste em atribuir a um paciente tal ou qual "diagnóstico", classificando-o, por exemplo, como obsessivo, ainda assim ele pode manifestar sintomas e modos de funcionamento que seriam qualificados como tipicamente histéricos.

O que acontece é que, se um sintoma se expressa desta ou daquela maneira, assim o faz por meio de uma forma de expressão - que é utilizada cotidianamente para outras funções, como a comunicação -, e toda a questão se desloca para como as diferentes formas de expressão se constituem e se desdobram. Daí a importância de se fazer uma reconstrução teórica do desenvolvimento do eu e sua relação com a realidade: a genealogia da forma pela qual um sintoma se apresenta se confunde com a história da invenção do modo de expressão que envolve aquela forma. É importante ressaltar esse aspecto. Para Ferenczi, os múltiplos modos de expressão têm uma história. Essa história se refere ao corpo, e ela se desdobra cada vez que da criança é exigido o reconhecimento de uma realidade que escapa ao seu controle.

\section{A formação dos modos de expressão}

Por um longo período de tempo, a criança não dispõe da linguagem verbal e, mesmo quando começa a desenvolvê-la, há "uma duração relativamente importante do tempo requerido para a aprendizagem da fala" (Ferenczi, 1910/1991, p. 112). Esse dado, evidente e até mesmo banal, desempenha um papel fundamental na teoria de Ferenczi: dá abertura para se pensar um período em que a linguagem ainda não foi desenvolvida e que, não obstante, é habitado pela invenção e uso de outras formas de expressão. Pode-se dizer que sua perspectiva é ainda mais radical, pois a constituição da linguagem não é entendida como o advento de uma ordem inédita que rompe ou aniquila tudo que a antecedeu. Pelo contrário, ela se desenvolve no decurso de um processo de diferenciação das outras formas de expressão, e essa diferenciação consiste na recombinação da mistura que há entre todas elas, ainda que em graus variáveis.

Ferenczi explicita basicamente três formas de expressão: a primeira é de natureza sensorial, a segunda envolve a dimensão motora e a última, por fim, tem como corolário a verbalização. Todas elas são qualificadas como Darstellungsmittel, meios de figuração ou de apresentação (Ferenczi, 1913/1927); e, em cada uma delas, circunscreve-se uma diversidade de ações, como, respectivamente, a alucinação e a imaginação, os movimentos descoordenados e os gestos organizados, a fala e o pensamento consciente (Ferenczi, 1913/1992). Entretanto, cada modo de expressão, seja ele qual for, condensa em si todos os demais, ainda que em graus diversos de mistura. Se uma criança muito pequena se exprime por meio do reinvestimento alucinatório de um estado anterior de satisfação, isso não exclui o fato de ela - concomitantemente à alucinação - realizar movimentos corporais, como agitar os braços e crispar os olhos, e vocalizar sons que podemos reconhecer como de descontentamento ante uma situação de carência.

Assim, cada modo de expressão implica em uma forma, uma configuração, uma organização na qual um aspecto (sensorial, motor ou verbal) parece sobressair em relação aos demais, como se todos estes se organizassem em torno daquele elemento principal. $\mathrm{O}$ fato de os outros processos não serem tão presentes não extingue a presença e mesmo a ação efetiva deles: se não os percebemos, é por uma questão de atenção, de seleção ou, para sermos mais precisos, por um processo de exclusão. Contudo tal exclusão não se faz sem consequências, e um bom exemplo disso, denunciado em diversos momentos por Ferenczi em sua obra, é a concepção segundo a qual o pensamento teria uma diferença de natureza em relação ao corpo (Ferenczi, 1932/1990). Ele defende justamente o contrário: o pensamento é corporal e, mais precisamente ainda, o pensamento consiste na mobilização de uma diversidade de ações motoras sutis ou grosseiras, visíveis ou imperceptíveis.

Consideramos que, ao compor sua narrativa sobre o desenvolvimento do sentido de realidade, Ferenczi tira da exclusão as formas de expressão que não se confundem com a linguagem verbal e lhes dá cidadania, tanto no sentido de colocá-las em cena como no de darlhes potência e estatutos singulares. A maneira que ele encontra para realizar tal gesto é procurar suas origens, acompanhar seus percalços, delinear suas trajetórias... em suma, é conceder-lhes uma história, uma história sobre sua constituição e desenvolvimento, tendo como cenário a relação da criança com a realidade (Ferenczi, 1913/1992). Essa história não tem uma estrutura linear e progressiva, como se os modos de expressão fossem aquisições que se justapusessem ordenadamente ao longo de uma linha evolutiva; ela tem, isto sim, uma arquitetura cíclica ou, melhor dizendo, espiralada. Três noções modelam essa peculiar arquitetura: onipotência, catástrofe e regressão. Na reconstrução teórica da gênese de cada modo de expressão, esses três movimentos se articulam de maneira inextrincável, e é somente na dinâmica dessa articulação, apenas no interior do seu jogo de forças, que conseguimos apreender o caráter cíclico e espiralado da narrativa de Ferenczi a propósito das origens dos modos de expressão.

Não é por uma razão fortuita que sua teoria adquire essa conformação, mas devido a uma posição sustentada de um jeito quase, poderíamos dizer, axiomático: não se pode conceber, nos processos vitais em geral ou nos psíquicos em particular, uma força espontânea que vise puramente o progresso e o aperfeiçoamento (Ferenczi, 1913/1992, 1924/1993). Se se insiste em falar em progressão ou evolução, se se usa o termo "desenvolvimento" para designar o percurso histórico 
da relação da criança com a realidade, então deve-se conceber a progressão como intrinsicamente traumática. Ela se dá sempre como resposta do vivente diante de uma catástrofe, nunca por algum tipo de programa interno que visa espontaneamente seu aprimoramento (Ferenczi, 1924/1993). E essa resposta consiste na efetivação de um movimento que busca retornar a um estado anterior à catástrofe, estado esse marcado por uma experiência de onipotência. Em outras palavras, diante de uma catástrofe, coloca-se em ação um movimento de regressão como tentativa de resgatar um estado de onipotência perdido, e é precisamente nesse movimento regressivo que se desdobra uma progressão - progressão no sentido de inventar algo novo para sobreviver na nova situação imposta pela catástrofe (Câmara, 2018, 2021).

A regressão é o processo que decididamente torna a narrativa cíclica e espiralada, na medida em que descreve uma dobra, uma curvatura daquilo que parecia ir para frente, fazendo-o flexionar-se, retorcer-se e projetar-se em direção ao passado. Contudo é preciso destacar que regressão não se confunde com reversibilidade. Reversibilidade tem o sentido de desfazer o que foi feito, como se o que está sendo desfeito nunca tivesse existido. A regressão, a seu turno, está na duração e dela não escapa. Se há um regresso, este implica e condensa toda a história que se desdobrou até aquele momento, incluindo a catástrofe e a própria trajetória que a regressão descreve.

A construção de Ferenczi talvez possa ser qualificada como descontinuísta, porque o desenvolvimento não se dá como um fluxo constante, mas como uma sucessão de estágios que são separados uns dos outros por catástrofes. Das catástrofes, seguem regressões. Desse processo em sua totalidade, surgem novas formas de vida, novos modos de expressão, que se estabilizam como momentos, etapas, estágios. No entanto é importante destacar que as catástrofes não aniquilam tudo o que as antecedeu. A catástrofe não é algo externo à história, mas algo imanente a própria história. As maneiras de viver a ela anteriores restam preservadas de algum jeito, e atuam e fazem presentificar seus efeitos nas sucessivas reconstruções e remodelações que geram novas formas de vida, novos modos de expressão.

Somente nesse sentido se pode entender porque, em Ferenczi, cada retorno, cada regresso, cada ciclo não consiste em uma repetição, mas, pelo contrário, envolve criação. Uma vez que a regressão está na duração, uma vez que ela carrega em si a história de tudo o que aconteceu e que continua acontecendo, uma vez, enfim, que a catástrofe não elimina a memória e a regressão percorre, de modo inverso, as trilhas dessa memória, não é possível retornar a um mesmo ponto de origem. $\mathrm{Se}$, como veremos, cada estágio é separado do outro por uma fratura, por uma falha catastrófica, não é menos verdade que esse estágio concentra, em si, tudo que se constituiu no estágio anterior, ainda que sob nova organização. Em suma, cada modo de expressão condensa aquela que a antecedeu, mas sob novos termos, novas condições, nova configuração.

\section{Os desdobramentos da onipotência}

O ponto de origem para o qual todo esforço de regressão se dirige é a onipotência e, mais especificamente, para um estado designado por Ferenczi como "onipotência incondicional" (Ferenczi, 1913/1992). Aliás, vale dizer que, em certos momentos de sua obra, o autor põe em questão se o movimento que anima a regressão seria uma pulsão ou, antes, uma força de atração, isto é, uma força que atrai o vivente a um estado inicial - seja o oceano, no caso dos seres terrestres, seja a morte, a completa dissolução no universo, no caso das crianças pequenas que não foram bem recebidas por suas famílias quando de seu nascimento (Ferenczi, 1924/1993, 1929/1992). De acordo com essa perspectiva, pois, a primeira experiência de onipotência pela qual a criança passou exerceria uma atração que seria tanto mais forte quanto mais críticas fossem as situações de catástrofe.

$\mathrm{Na}$ teoria ferencziana, o conceito de onipotência envolve três camadas semânticas que se interpenetram. Em primeiro lugar, é definido como um estado de absoluto contentamento ou, a bem da precisão, um estado de ter tudo o que se poderia querer e não ter mais nada a desejar (Ferenczi, 1913/1992). Apesar de essa descrição sobre o sentimento de onipotência ser eloquente, a generalidade dessa definição a torna passível de ser confundida com, por exemplo, mero estado de satisfação. O segundo sentido, mais profundo, diz respeito a um jeito de apreender ou de conceber como se encadeiam os fenômenos do mundo: todos os acontecimentos, todas as relações de causa e efeito se condicionam aos movimentos de desejo do ser onipotente ou daquele que a criança acredita deter a onipotência. Essa acepção revela o poder que o termo onipotência carrega no seu próprio nome: o poder de "violar, com a ajuda desses gestos anódinos, a ordem normal do universo" (Ferenczi, 1913/1992, p. 46). Seja o obsessivo que não consegue se desvencilhar da crença de que um pensamento seu é capaz, por si só, de matar alguém que ama; seja a criança que, por um movimento corporal qualquer, crê obter aquilo que deseja sem a intermediação dos adultos - enfim, o fato é que em ambos os casos o universo e todos os acontecimentos que ele engloba estão completamente submetidos ao poder do ser onipotente (Ferenczi, 1913/1992).

A terceira camada semântica do conceito de onipotência, intimamente interligada às outras duas, refere-se a uma mistura entre o desejo e a ação, por um lado, e entre o pensamento e a ação, por outro. Sabemos que o pensamento é aquilo que se interpõe entre o desejo e a ação, tornando-se a condição que possibilita a abertura de um intervalo temporal entre ambos os processos: só se age após o pensamento delinear uma relação de identidade entre o que se deseja e o que se apresenta à percepção (Freud, 1895/1995, 1911/2006). Entretanto, na experiência de onipotência, desejo, pensamento e ação são uma só coisa. Agir é suficiente para materializar aquilo que se deseja, e aquilo que é materializado se identifica com o desejado. Desejar é agir, pensar é agir, 
mas o contrário também é verdadeiro: agir é desejar, agir é pensar. Os modos de expressão inventados pela criança guardam essa origem sobretudo mágica, antes de pretenderem ter uma função de comunicação.

Engana-se quem queira opor a magia ao real. $\mathrm{Na}$ onipotência, o desejo que se materializa na ação produz modificações reais no mundo, e prova disso é todo o ambiente em volta da criança se mobilizar para atendê-la, por exemplo, em seu choro. Não por acaso, para Ferenczi, a onipotência não é uma experiência mítica, mas uma experiência concreta, real (Ferenczi, 1913/1992). É verdade que se pode dizer que a condição da criança é de desamparo, na qual precisa de alguém que dela cuide para satisfazer suas necessidades e desejos, por mais básicos que sejam (Freud, 1895/1995). Todavia conceber as coisas sob esses termos é partir do ponto de vista-e, poderíamos acrescentar, da lógica - de um adulto que testemunha a situação e que decide o que é real ou não. Ao propor que a onipotência é uma experiência real, Ferenczi inverte a perspectiva, tentando se colocar na posição da criança, ou melhor, no interior de sua experiência. Isso não apenas devido a uma certa empatia que, conforme vimos, confessa ter pela mente infantil (Ferenczi, 1926/1993), mas também por uma necessidade ética: para ele - e isso é uma das coordenadas mais importantes que traça para a clínica do traumático -, um dos "pecados" da psicanálise seria o de abordar os fenômenos infantis com uma visão adulta (Ferenczi, 1932/1990; 1933/1992).

Vimos que cada regressão, enquanto resposta a uma catástrofe, tem como horizonte reatualizar uma situação anterior de onipotência. Ferenczi concebe que há um estado primeiro de onipotência, espécie de marco zero que constitui o lugar para onde todo esforço de regressão se dirige ou de onde toda a atração de regressão imanta. Esse lugar é o interior do corpo da mãe (Ferenczi, 1924/1993). Na vida intrauterina, o feto é provido, pelo organismo materno, de todas as suas necessidades sem que tenha de realizar qualquer tipo de esforço ou demanda. Nas palavras de Ferenczi, o feto deve ter, "pela própria circunstância de existir, impressão de que é realmente onipotente. ... É o que o feto poderia pretender no que lhe diz respeito, já que possui constantemente tudo o que é necessário à satisfação de suas pulsões" (Ferenczi, 1913/1992, p. 42). Se posteriormente o sujeito sofreu negligência por parte do ambiente de maneira a não conseguir mais reviver experiências de onipotência, o fato é que, por ter vivido no útero, ele pôde usufruir de tal sentimento ao menos nesse período de sua vida.

Nesse caso específico no qual a criança habita o útero, o estado de onipotência é, portanto, uma experiência real. Mesmo com a catástrofe do nascimento, em que ela é expulsa e banida do corpo da mãe para habitar um ambiente estranho e inóspito, a experiência de onipotência sobrevive como algum tipo de memória, como algum tipo de impressão, que, fazendo parte de sua história, norteia o anseio de revivê-la (ou fixa um campo de atração que puxa a criança no sentido de experimentá-la novamente): “os traços dos processos psíquicos intrauterinos", afirma Ferenczi (1913/1992, p. 42), "não deixam de exercer influência sobre a configuração do material psíquico que se manifesta após o nascimento" (p. 42). Essa observação se coaduna com o que foi discutido há pouco, e é preciso destacá-la para o que segue: as catástrofes não extinguem a história, não aniquilam a memória. Essa história sobrevive e exerce uma ação decisiva sobre os acontecimentos posteriores, mais especificamente sobre a constituição de novos modos de expressão.

Entretanto alguma coisa muda: abrigado no corpo materno, o feto vivia uma onipotência incondicional, quer dizer, um mundo no qual não era necessário satisfazer nenhuma condição para ter o que se poderia querer. Distintamente, após o nascimento, a criança é capaz de restabelecer experiências de onipotência, mas ao custo de aquiescer a certas condições impostas pelo ambiente das quais ela desconhece e que, não obstante, cumpre de algum modo. Não à toa, Ferenczi denomina os retornos à onipotência que seguem ao nascimento como estágios de "onipotência condicional", nos quais a criança precisa se afirmar por meio de movimentos corporais progressivamente mais complexos, a fim de satisfazer as novas condições que se impõem (Ferenczi, 1913/1992).

\section{Catástrofe e afirmação}

Entre a vida dentro do corpo da mãe e o nascimento, uma catástrofe. Talvez nenhum evento a nível ontogenético represente com tanta clareza o que é catástrofe como o nascimento. Mas, afinal, como podemos, de acordo com a teoria ferencziana, defini-la? A catástrofe é um evento que anula, de maneira súbita e inapelável, todas as condições de vida que existiam até então, gerando, no lugar delas, novas condições que se impõem ao vivente (Câmara et al., 2017; Câmara \& Herzog, 2018). Não se pode negociar com elas e tampouco há alguma notícia ou informação de como funcionam ou o que especificamente exigem; a única coisa que resta a ser feito é um remanejamento radical por parte do sujeito. Se há o brusco desaparecimento de certas condições com as quais ele se acomodara e sua substituição por novas condições, o remanejamento do qual se exige é a criação de novas formas de vida que as leve em conta, para que esta - a vida - possa continuar a ser viável.

Com efeito, o nascimento é um acontecimento que envolve a perda de uma série de condições de vida às quais o feto estava perfeitamente adaptado (Ferenczi, 1913/1992, 1924/1993). Se antes ele se encontrava abrigado em um ambiente úmido em que não precisava sequer sentir o peso do próprio corpo; onde a temperatura era aconchegante e constante; onde o impacto das excitações era amortecido; onde sentia, por fim, uma quietude isenta de desejos, pois que tudo o que necessitava lhe era prontamente dado - se, afinal, o modo de vida do feto estava construído de acordo com essas condições, após a catástrofe do nascimento, tudo muda. O mundo agora é seco e o corpo sente os efeitos da gravidade; variações de calor e frio ameaçam 
a constância de temperatura e um caos de excitações sensoriais cruas acossam a criança; ela passa a sentir alienação ante um mundo estranho, angústia diante de acontecimentos imprevisíveis, anseio de que tudo volte a ser como antes.

A catástrofe é, pois, um evento externo, ou melhor, um acontecimento que vem de fora, produzindo uma multiplicidade de fraturas nas condições de vida de que a criança gozava, a ponto de torná-las insustentáveis. Assumindo-se que é a partir desse estado de coisas que a criança deve inventar um novo modo de vida, percebemos a importância da ideia de catástrofe na teoria ferencziana: é sempre por um evento de fora que o sujeito é impulsionado a criar novas maneiras de viver, nunca por força espontânea. Conforme já dissemos, toda progressão é traumática. E essa progressão, essa criação, essa transformação se faz por um processo de adaptação (Anpassung) às novas condições que emergiram (Ferenczi, 1939/1992).

Apesar de confessar a influência das teses darwinista e lamarckista em sua concepção de adaptação, Ferenczi (1928/1992) delas se afasta de maneira decisiva. Para Darwin, que lida com populações, e não com um indivíduo isolado, a adaptação é algo colocado de partida: quem é mais bem adaptado é selecionado na luta pela sobrevivência. Lamarck, por sua vez, apesar de tratar do indivíduo isolado e de não colocar a adaptação como fato inicial, entende que é pelo exercício de uma função que a adaptação ocorre (Ferenczi, 1928/1992). Em Ferenczi, a adaptação não é um fato já colocado de saída; pelo contrário, se dá como um processo que se desdobra diante de uma catástrofe e ao longo dela (Ferenczi, 1924/1993, 1939/1992). Além disso, apesar de não lidar com populações, mas com uma criança, esta não pode ser tomada isoladamente: a adaptação a envolve, assim como o meio que a atende (Ferenczi, 1939/1992). Por fim, Ferenczi não pensa a adaptação como o exercício de uma função cuja repetição a tornaria mais bem afeita às novas condições, pois, em primeiro lugar, de que função se trataria? Com base em que seria essa função selecionada entre as demais?

A adaptação às novas condições de vida não consiste em uma total submissão a elas, mas em uma apropriação delas com o fim de regredir ao estado de onipotência. Esse é o elemento diferencial que torna a noção de adaptação, em Ferenczi, distante da dos seus antecessores: em concomitância à catástrofe - $\mathrm{a}$ isso que vem de fora -, ele concebe uma força imanente, algo que parece vir de dentro e que busca se apoderar das condições e criar algo em cima delas, mas não com o fim de aperfeiçoar uma função ou o que quer que seja, mas para tão somente regredir a um estado que precisou ser abandonado (Ferenczi, 1924/1993).

Essa concepção original de adaptação atinge toda sua potência com o conceito de afirmação do desprazer, que pode ser explicado da seguinte maneira: se o psiquismo é regido pelo princípio do prazer, por que a criança abandonaria formas consolidadas de obtenção de prazer e aceitaria o incremento de desprazer, intrínseco a tal movimento de abandono? Em outros termos, o que a faria afirmar um desprazer, em vez de manter-se com o prazer a que se acomodara? Isso só poderia ocorrer porque a criança - e todo vivente - é capaz de antecipar múltiplos cenários futuros e "calcular" aquele que produz menos desprazer": no caso em pauta, ou ela insiste em manter um modo de obtenção de prazer que não é mais possível como tal ou o abandona para criar outra forma de experimentar prazer. O que produz menos desprazer pode ser sentido, em comparação ao outro cenário, como um "prazer relativo" e é, nesta medida - e somente nesta - que se pode afirmar um desprazer (Ferenczi, 1926/1993).

Em sua articulação à ideia de adaptação diante de acontecimentos catastróficos, o conceito de afirmação do desprazer envolve o movimento de a criança aceitar, ativamente, destruir partes de si para reconstruir, ou melhor, para criar, a partir dos escombros e com esses escombros, uma nova forma de vida, um novo modo de existência (Ferenczi, 1926/1993, 1939/1992; Câmara et al., 2017). E isso ocorre somente com o movimento de se apoderar, quer dizer, de se apropriar - de tornar próprias para si - das condições que emergiram diante da catástrofe: "a afirmação de um desprazer só é possível após o abandono da defesa contra os objetos que são fontes de desprazer e sua negação, e após a transformação em impulsos internos das excitações que proveem desses objetos, incorporando-os ao ego" (Ferenczi, 1926/1993, p. 404, grifos nossos).

A adaptação é, assim, uma verdadeira afirmação do vivente diante da catástrofe, e ela não pode ser entendida a partir de uma ideia, a nosso ver simplista, que a conceberia como o triunfo unilateral da pulsão de vida. O conceito de vida, tão complicado, mas ao mesmo tempo tão caro a Ferenczi, não pode ser entendido dessa maneira. A vida envolve não apenas a pulsão de vida, mas também - e intrinsicamente - destruição e mortalidade (Ferenczi, 1924/1993). Neste sentido, em Ferenczi a vida é algo que se afirma, algo que se afirma a todo o momento, e essa afirmação às vezes (senão sempre) só pode se dar com processos de autodestruição.

Aliás, gostaríamos de destacar, em sua justa medida, o termo Bejahung, "afirmação", cujas repercussões políticas são inegáveis. Na catástrofe, o vivente não se submete inteiramente às novas condições, mas afirma uma posição diante delas, delas se apropriando. Não é possível negociar com elas e tampouco adiá-las, é certo; mas isso não significa que a criança não possa jogar com elas, criar jeitos de manejá-las e de torná-las suas. As diferentes formas de expressão são resultado desse movimento de apropriação das novas condições de vida que surgem após as catástrofes; em outras palavras, os próprios modos de expressão se constituem como uma afirmação singular da criança e de sua existência.

3 O cálculo a que Ferenczi se refere não é um processo cognitivo consciente. Ele concebe que todas as formas de vida, mesmo as mais elementares, têm uma capacidade inconsciente de calcular determinados processos (Ferenczi, 1926/1993, 1920/1992). 


\section{Complexificação, multiplicidade e unicidade}

Até o momento, tratamos a articulação da onipotência, da catástrofe e da regressão sob o viés da noção de condição e da adaptação. A condição é aquilo de que a criança se apropria para regressar à onipotência, e tal apropriação acontece com a invenção de novos modos de expressão, estando aí a noção de adaptação. Um terceiro elemento que faz parte da narrativa de Ferenczi sobre as passagens dos sentidos de realidade é a crescente complexificação do desejo da criança, isto é, a multiplicação de qualidades que vão constituindo seus movimentos de desejo (Ferenczi, 1913/1992). Tal complexificação tem o sentido de gerar e multiplicar novas maneiras pelas quais uma forma de expressão já inventada pode se exprimir.

Ora, as novas condições de vida trazem consigo perspectivas inéditas de experienciar o mundo, novas maneiras de percebê-lo, de senti-lo, de estar nele e nele se deslocar. A introjeção dessas experiências que ganham corpo, tanto em decorrência de vivências sensoriais quanto motoras, desdobra novas qualidades para os desejos - dando-lhes novas cores, tonalidades, formas, aspectos -, assim como cria novos desejos, multiplicando-os e pluralizando-os.

Um exemplo básico, mas eloquente a esse respeito refere-se à experiência de satisfação, tal como Ferenczi (1910/1991) a concebe: "no início", diz ele, "a criança só gosta da saciedade, porque ela aplaca a fome que a tortura - depois acaba gostando também da mãe, esse objeto que lhe proporciona a saciedade" (p. 85, grifos no original). Em outros termos, primeiro a criança ama a sensação e depois o objeto que provocou essa sensação. Assim, as experiências pelas quais a criança passa após o nascimento a levam progressivamente a fabricar novos objetos para desejar e até mesmo novos aspectos do mesmo objeto - outros cheiros, outras imagens etc. A consequência dessas introjeções é a extensão de coisas que se tornam a matéria expressiva, quer dizer, a constituição de novas imagens, movimentos e sons com que a criança pode se relacionar, multiplicando e diversificando as qualidades que figura por meio dos diferentes modos de expressão.

Além do fator de complexificação de uma forma de expressão, Ferenczi concebe também uma multiplicidade de formas de expressão, sendo que, entre elas, não há diferença de natureza, mas de grau. Essa concepção implica duas consequências que se relacionam de maneira paradoxal. Por um lado, Ferenczi insiste em evidenciar a diferença, a especificidade de cada uma delas, mas, por outro, defende um pano de fundo comum a todas: em suma, o paradoxo envolve a multiplicidade e a unicidade dos modos de expressão. Começando por este último ponto, vale enfatizar que a linguagem verbal é por ele qualificada como, literalmente, um "körperlichen Mittel", isto é, como um meio físico, um meio material, e o mesmo vale para os outros modos de expressão (Ferenczi, 1913/1927, p. 75). Isso significa dizer que Ferenczi os concebe em toda sua materialidade: todas os modos de expressão são fundamentalmente corporais. Assim, o corpo é o pano de fundo comum de onde os mais diversos modos se derivam e por meio do qual se apresentam. Toda expressão, em Ferenczi, é corporal.

A história das relações da criança com o entorno e a experiência clínica respondem pelo outro ponto, qual seja, o de Ferenczi sustentar uma diferença entre os modos de expressão, não obstante entendendo que todos eles são corporais. Reconstruir a história do desenvolvimento do eu diante da realidade deve levar em conta, como vimos, que há um longo período no qual a criança, não tendo ainda desenvolvido a linguagem verbal, constitui outras maneiras de se expressar. Nessa narrativa, Ferenczi descreve que a criança imagina e alucina antes de organizar seus movimentos corporais em forma de gestos, e que este último modo de expressão adquire predominância antes de ser deslocado a um segundo plano pela linguagem verbal (Ferenczi, 1913/1992). Cada modo se organiza em tempos diversos da história da criança, sendo convocado a responder a crises que se instalam na sua relação com o mundo: com a progressiva expansão dos limites e das possibilidades do corpo, os desejos da criança se tornam mais complexos, por um lado, e os adultos excluem de seu campo perceptivo e interpretativo demandas cuja expressão não parecem condizer mais com a dita maturação da criança, por outro (Ferenczi, 1913/1992). Não se exige de um recém-nascido que se expresse da mesma forma que uma criança com uma década de vida e vice-versa.

Ora, foi a experiência clínica que motivou Ferenczi a elaborar essa reconstrução teórica das relações da criança com a realidade: seja para responder à indagação de como um sintoma se apresenta (e não o que representa), seja por entender que a história de um sujeito pode se expressar de outras formas além da fala. De fato, a contrapelo da norma do senso comum, um paciente que tem muitas décadas de vida pode, não obstante e em circunstâncias específicas, se expressar como uma criança pequena - é o caso da regressão -, e uma criança pequena pode se expressar como um adulto com muitas décadas de vida - é o caso da prematuração traumática. Ferenczi era muito sensível a isso, e a tal ponto que, nos últimos anos de sua trajetória, esmaeceu definitivamente a fronteira que separa a análise de adultos da análise de crianças (Ferenczi, 1931/1992). Não à toa, disse, em tom de crítica aos psicanalistas: "falamos muito em análise de regressão ao infantil, mas é manifesto que nem nós mesmos acreditamos a que ponto temos razão" (Ferenczi, 1933/1992, p. 100).

Apesar de o método analítico se afiançar principalmente na produção verbal, defendemos a perspectiva de que, desde seus primeiros textos, Ferenczi sustenta a posição de não excluir os outros modos de expressão. Por não tê-los excluído, entrou em contato com muitos planos de realidade, incluindo aí o do trauma. Com efeito, ao dar cidadania aos outros modos de expressão, Ferenczi não apenas os colocou em cena, 
como garantiu que fossem recebidos e pensados em toda sua especificidade. O resultado desse gesto é o de fazer com que a linguagem verbal não seja separada fundamentalmente dos demais modos de expressão, como se fosse o zênite de um processo evolutivo que, por algum motivo destacada do resto, serviria de modelo para pensá-los a posteriori de acordo com suas próprias regras.

Talvez esteja aí a relevância maior do modelo das passagens do sentido de realidade imaginado por Ferenczi: a linguagem não é apartada do corpo, e o corpo não é entendido como algo que excede ou escapa de um pretenso poder da linguagem. Os diversos modos do corpo se expressar têm sua própria potência singular, e uma não precisa estar subsumida a outra nem ser transliterada para uma específica, supostamente superior. Em suma, Ferenczi rompe com a hegemonia da linguagem e defende uma pluralidade da expressão. As consequências disso para a clínica são, a nosso ver, incalculáveis, e a principal delas pode ser, desde já, indicada: as manifestações corporais não são índices de um suposto déficit de simbolização da linguagem. O que está em jogo em Ferenczi é outra coisa: ele defende a pluralidade dos modos de expressão, a multiplicidade expressiva do corpo.

\section{Ferenczi and the constitution of the forms of expression}

Abstract: Throughout his work, Sándor Ferenczi concerns himself with the dimension of the body in the psychoanalytic experience, framing it predominantly from the point of view of expression. This paper presents a reading, based on his theory, on the constitution of multiple modes of expression. To do so, we propose six ideas organized in two parallel and complementary series: the first involves the notions of omnipotence, catastrophe, and regression; the second groups the ideas of condition, adaptation, and complexification.

Keywords: Ferenczi, expression, body, psychoanalysis.

\section{Ferenczi et la constitution des formes d'expression}

Résumé : Tout au long de son œuvre, Sándor Ferenczi s'intéresse à la dimension du corps dans l'expérience psychanalytique, en l'encadrant principalement du point de vue de l'expression. Cet article présente une lecture, basée sur sa théorie, de la constitution de multiples modes d'expression. Pour cela, nous proposons six idées organisées en deux séries parallèles et complémentaires : la première implique les notions d'omnipotence, de catastrophe et de régression ; la seconde regroupe les idées de condition, d'adaptation et de complexification.

Mots-clés : Ferenczi, expression, corps, psychanalyse.

\section{Ferenczi y la constitución de las formas de expresión}

Resumen: A lo largo de su obra, Sándor Ferenczi trata de la dimensión del cuerpo en la experiencia psicoanalítica, concibiéndola predominantemente desde el punto de vista de la expresión. Este trabajo presenta una lectura, basada en su teoría, sobre la constitución de múltiples modos de expresión. Para ello, proponemos seis ideas organizadas en dos series paralelas y complementarias: la primera involucra las nociones de omnipotencia, catástrofe y regresión; la segunda agrupa las ideas de condición, adaptación y complejización.

Palabras clave: Ferenczi, expresión, cuerpo, psicoanálisis.

\section{Referências}

Câmara, L. (2018). Modulações do corpo: expressão e impressão na teoria ferencziana (Tese de doutorado). Instituto de Psicologia, Universidade Federal do Rio de Janeiro, Rio de Janeiro, RJ.

Câmara, L. (2021). Ferenczi e a psicanálise: corpo, expressão e impressão. São Carlos, SP: EdUFSCar.
Câmara, L., \& Herzog, R. (2014). Um e outro: Ferenczi e a epistemologia. Psicologia USP, 25(2), 125-133. doi: 10.1590/0103-656420130041.

Câmara, L., \& Herzog, R. (2018). Um prefácio imaginário para Thalassa. Estudos e Pesquisas em Psicologia, 18(1), 244-260. doi: 10.12957/epp.2018.38119. 
Câmara, L.; Herzog, R., \& Canavêz, F. (2018). A palavra e o corpo: impressão e expressão na teoria ferencziana. In A. Maciel Jr. (Org.), Trauma e ternura: a ética em Sándor Ferenczi (pp. 73-82). Rio de Janeiro, RJ: 7Letras.

Câmara, L., Herzog, R., Pinheiro, T., Verztman, J., PachecoFerreira, F., \& Viana, D. (2017). Autotomie et clivage: de l'image au concept. Revue Canadienne de Psychanalyse, 25(1-2), 103-117.

Ferenczi, S. (1927). Über passagère Symptombildungen währendderAnalyse(PassagèreKonversion, Substitution, Illusion, Halluzination, "Charakterregression" und “Ausdrucksverschiebung”). In S. Ferenczi, Bausteine zur Psychoanalyse, band II: Praxis (pp. 9-25). Leipzig: Internationaler Psychoanalytischer Verlag. (Trabalho original publicado em 1912)

Ferenczi, S. (1927). Entwicklungsstufen des Wirklichkeitssinnes. In S. Ferenczi, Bausteine zur Psychoanalyse, band I: Theorie (pp. 62-83). Leipzig/: Internationaler Psychoanalytischer Verlag. (Trabalho original publicado em 1913)

Ferenczi, S. (1927). Das Problem der Unlustbejahung (Fortschritte in der Erkenntnis des Wirklichkeitssinnes). In S. Ferenczi, Bausteine zur Psychoanalyse, band I: Theorie (pp. 84-100). Leipzig: Internationaler Psychoanalytischer Verlag. (Trabalho original publicado em 1926)

Ferenczi, S. (1939). Hysterische Materialisationsphänomene (Gedanken zur Auffassung der hysterischen Konversion und Symbolik). In S. Ferenczi, Bausteine zur Psychoanalyse, band III: Arbeiten aus den Jahren (pp. 129-147). Budapest: Verlag Hans Huber. (Trabalho original publicado em 1919)

Ferenczi, S. (1990). Diário clínico. São Paulo, SP: Martins Fontes. (Trabalho original publicado em 1932)

Ferenczi, S. (1991). Palavras obscenas: contribuição para a psicologia do período de latência. In S. Ferenczi, Psicanálise I (A. Cabral, Trad., pp. 109-120). São Paulo, SP: Martins Fontes. (Trabalho original publicado em 1910)

Ferenczi, S. (1992). O desenvolvimento do sentido de realidade e seus estágios. In S. Ferenczi, Psicanálise II (A. Cabral, Trad., pp. 39-53). São Paulo, SP: Martins Fontes. (Trabalho original publicado em 1913)

Ferenczi, S. (1992). Matemática. In S. Ferenczi, Psicanálise IV (A. Cabral, Trad., pp. 177-187). São Paulo, SP: Martins Fontes. (Trabalho original publicado em 1920)

Ferenczi, S. (1992). A adaptação da família à criança. In S. Ferenczi, Psicanálise IV (A. Cabral, Trad., pp. 1-13). São Paulo, SP: Martins Fontes. (Trabalho original publicado em 1928)
Ferenczi, S. (1992). A criança mal acolhida e sua pulsão de morte. In S. Ferenczi, Psicanálise IV (A. Cabral, Trad., pp. 47-51). São Paulo, SP: Martins Fontes. (Trabalho original publicado em 1929).

Ferenczi, S. (1992). Confusão de língua entre os adultos e a criança (a linguagem da ternura e da paixão). In S. Ferenczi, Psicanálise IV (A. Cabral, Trad., pp. 97-106). São Paulo, SP: Martins Fontes. (Trabalho original publicado em 1933)

Ferenczi, S. (1992). Notas e fragmentos. In S. Ferenczi, Psicanálise IV (A. Cabral, Trad., pp. 235-284). São Paulo, SP: Martins Fontes. (Trabalho original publicado em 1939)

Ferenczi, S. (1993). Thalassa: ensaio sobre a teoria da genitalidade. In S. Ferenczi, Psicanálise III (A. Cabral, Trad., pp. 255-325). São Paulo, SP: Martins Fontes. (Trabalho original publicado em 1924)

Ferenczi, S. (1993). O problema da afirmação do desprazer (Progressos no conhecimento do sentido de realidade). In S. Ferenczi, Psicanálise III (A. Cabral, Trad., pp. 393404). São Paulo, SP: Martins Fontes. (Trabalho original publicado em 1926).

Freud, S. (1995). Projeto de uma psicologia. Rio de Janeiro, RJ: Imago. (Trabalho original publicado em 1895)

Freud, S. (2006). As neuropsicoses de defesa. In Edição standard brasileira das obras psicológicas completas de Sigmund Freud (J. Salomão, Trad., Vol. 3, pp. 51-72). Rio de Janeiro, RJ: Imago. (Trabalho originalmente publicado em 1894).

Freud, S. (2006). Três ensaios sobre a teoria da sexualidade. In Edição standard brasileira das obras psicológicas completas de Sigmund Freud (J. Salomão, Trad., Vol. 7, pp. 119-231). Rio de Janeiro, RJ: Imago. (Trabalho original publicado em 1905)

Freud, S. (2006). Formulações sobre os dois princípios do funcionamento mental. In S. Freud, Edição standard brasileira das obras psicológicas completas de Sigmund Freud (J. Salomão, Trad., Vol. 12, pp. 233-244). Rio de Janeiro, RJ: Imago. (Trabalho original publicado em 1911)

Freud, S. (2006). Tipos de desencadeamento da neurose. In S. Freud, Edição standard brasileira das obras psicológicas completas de Sigmund Freud (J. Salomão, Trad., Vol. 12, pp. 247-255). Rio de Janeiro, RJ: Imago. (Trabalho original publicado em 1912)

Freud, S. (2014). Inibição, sintoma e angústia. In Obras completas (P. C. Souza, Trad., Vol. 17, pp. 13-123). São Paulo, SP: Companhia das Letras. (Trabalho original publicado em 1926)

Recebido: 18/11/2019 Aprovado: 03/10/2021 